\title{
Advanced Glycation End Products (AGEs) in Food: Focusing on Mediterranean Pasta
}

\author{
Abate $\mathbf{G}^{1}$, Delbarba $A^{2}$, Marziano $\mathbf{M}^{1}$, Memo $\mathbf{M}^{1}$ and Uberti $\mathbf{D}^{1,2^{*}}$ \\ ${ }^{1}$ Department of Molecular and Translational Medicine, University of Brescia, Brescia, Italy. \\ ${ }^{2}$ Diadem Ltd, Spin Off of Brescia University, Brescia, Italy. \\ *Corresponding author: Uberti D, Department of Molecular and Translational Medicine, University of Brescia, 25123 Brescia, Italy, Tel: +39-0303717509; E-mail: \\ daniela.uberti@unibs.it
}

Rec Date: Nov 16, 2015; Acc Date: Nov 26, 2015; Pub Date: Dec 03, 2015

Copyright: (c) 2015 Abate G, et al. This is an open-access article distributed under the terms of the Creative Commons Attribution License, which permits unrestricted use, distribution, and reproduction in any medium, provided the original author and source are credited.

\begin{abstract}
Advanced glycation end products, also known as glycotoxins, are a diverse group of highly oxidant compounds with pathogenic significance in aged-chronic disease, including diabetes, cardiovascular disease and neurodegenerative disease. They are produced physiologically in the body when reducing sugar binds to a free amino acid group of macromolecules. Thus conditions such as hyperglycemia and/or oxidative stress can favor AGE product formation, contributing to ageing processes and the exacerbation of pathological states. Beside endogenous AGEs, dietary AGE intake contributes significantly to the body AGE pool. It assumes that if dietary AGE intake gets lower, any chronic disease, such as diabetes and cardiovascular disease can be ameliorated, and even cured. For this reason, recently great attention has been made on the identification and quantification of AGE products in the consumed foods. Here we reviewed some knowledge, found in literature, concerning the formation of AGEs in food, their gastrointestinal absorption, and their toxic effects. In addition original data on AGE content in the Mediterranean pasta was discussed in relation to their production processes and cooking time.
\end{abstract}

Keywords: Dietary advanced glycation end products; Amadori products; Maillard reaction; Mediterranean pasta; Oxidative stress; Inflammation; Age-related disease

\section{Abbreviations: \\ AGEs: Advanced Glycation End products; dAGEs: Dietary Advanced Glycation End products; FruLys: lactulosyllysine; GO: Glyoxal; MGO: MetylGlyoxal; CL: Carboxy-lysine; CML: N- carboxymethyllysine; ECM: Extracellular Matrix; ROS: Reactive Oxygen Species.}

\section{Introduction}

Advanced glycation end products (AGEs) are a heterogeneous group of compounds formed by Maillard chemical reaction, which refers to a non-enzymatic glycation of free amino groups of proteins, lipids or nucleic acids by reducing sugars and reactive aldehydes [1]. In biological system the process of AGE formation begins under hyperglycemic and/or oxidative stress conditions, followed by the conversion of reversible formed Schiff-base adducted to covalently bound Amadori rearrangement products. Then Amadori products can undergo further chemical reactions that result in the AGE formation [2]. AGEs are formed continuously in the body, as a part of normal metabolism, but if excessively high, they reach tissue and circulation and can become pathological [3].

Their toxic effects are essentially related to their ability to promote oxidative stress and inflammation by binding to cell surface receptors or cross-linking with body proteins, altering their structure and function $[3,4]$.
AGEs also exist in foods, and are named dietary AGEs (dAGEs). dAGEs can be already present in raw materials: different types of culturing, breeding and technical manipulation can affect their formation. Furthermore food processing, storage and cooking can contribute to increase dAGE content in final products [5-10].

Therefore, diet is a large source of dAGEs. Recently, different studies on mice and human have demonstrated that dAGEs can be absorbed at intestinal level, and be potentially toxic $[1,3,4]$.

The notion that low-dAGE intake reduced markers of oxidative stress and inflammation, not only in patients with diabetes [11] or kidney disease [12,13], but also in healthy subjects [14], suggested that avoidance of dAGE-rich food could help in ameliorate chronic pathological conditions and in maintaining the healthy ageing status.

Here we reviewed some knowledge, found in literature, concerning the formation of AGEs in food, their gastrointestinal absorption, and the mechanisms at the base of their toxic effects. In addition original data on dAGE content in the Mediterranean pasta were discussed in relation to production processes and cooking times.

\section{Dietary AGEs}

It has been well known that factors affecting AGE formation in foods include their composition, temperature, exposure to air when, for example the natural protective covering is damaged, humidity, $\mathrm{pH}$, and methods and duration of cooking $[1,15,16]$. Usually, foods high in lipid and protein content exhibit the highest dAGE levels. For example, fat and meat contain 30-and 12-fold higher AGE content than carbohydrate meal respectively [16]. Temperature and method of cooking appear to be more critical to AGE formation than cooking time. This is evidenced by the higher dAGE values of samples grilled at 
temperatures of $230^{\circ} \mathrm{C}$ for shorter cooking times when compared to samples boiled in liquid media at $100^{\circ} \mathrm{C}$ for longer periods $[1,16]$

Clearly, meat and meat-derived products, processed at high, dry heat such as in broiling, grilling, frying, and roasting are major sources of dAGEs. Alternative cooking methods, such as boiling and stewing, allow daily dAGE ingestion to be reduced by up to $50 \%$, keeping the same primary nutrients [17].

There are many strategies to reduce the dAGE intake. Some herbs, condiments and spices, have been reported to have intrinsic antiglycation activity $[6,18]$. For example, pre-treatment of meats with lemon, vinegar or with any acidic marinade before cooking has a significant effect in preventing the excessive increase of dAGE content. Dearlove and colleagues [19] demonstrated that polyphenols found in culinary herbs like sage, marjoram, tarragon, and rosemary are poten inhibitors of fructose-mediated protein glycation. Spice extracts, such as cloves, ground Jamaican allspice, and cinnamon, were also found to be glycation inhibitors, even stronger than herb extracts [19]. Since foods mainly composed of carbohydrates (e.g., starches, fruits, vegetables, and milk) contain the lowest AGE concentrations, another strategy to reduce dAGE intake consists in implementing the use of these healthy foods instead to eat full-fat cheeses, meats, and highly processed foods.

It is well established that Maillard reactions modify the nutritional value of food, with loss of availability of essential amino acids, vitamin $\mathrm{C}$ as well as important metals such as copper, zinc and iron. In addition these reactions produce toxic final products affecting human health.

The cascade of reactions that begins with glycosylation at amino groups of Lysine or other amino acids, (arginine, histamine, tryptophan and cysteine) gives rise to a plethora of advanced end products, some of which have been well investigated in food. Pentosidine that forms by protein-bound crosslink during advanced stages of Maillard reaction occurs usually during heating and storage [10]. Glyoxal (GO) and MetylGlyoxal (MGO) work as precursors for more complex AGE crosslinks, such as pentosidine and glucosepane, and are well examined for example in bakery products and edible oil [7]. Carboxy-lysine (CL) and N-carboxymethyllysine (CML) are produced by multiple pathways, for example CML may be formed by oxidative cleavage of the Amadori product or by reaction with GO with Lysine residues [9]. CML is also formed during lipid peroxidation reactions and during auto-oxidation of ascorbate. CML adducts are accumulated over time during food production processes and this is considered a potential hazard to human health. Lipeng et al. [9] suggested that preventing the formation of CML through the addition of inhibitors or changing food processing conditions, could contribute in controlling food-derived AGEs. Semba et al. showed that the majority of urinary CML levels derived from food, even if CML can also be formed endogenously [20].

In the tentative to define a high or low AGE diet different authors measured AGE content in usual daily food intake. The average dietary AGE intake in a cohort of healthy adults from New York City area was found to be nearly $15000 \mathrm{KU} /$ day [21]. In on other study, Goldberg et al. [1] analyzed 3-day food record from 34 healthy individuals and 40 type 2 diabetic patients. The mean daily AGE intake was around 16000 $\mathrm{KU} /$ day for healthy individuals and $18000 \mathrm{KU} /$ day for diabetic patients. In these latter patients the increased AGE intake was principally due to the cooking methods, which included broiled, fried, grilled and roasted food.

\section{dAGEs intestinal absorption}

The potential biological role of exogenous AGEs has been ignored for long time because of the assumption that they undergo negligible gastrointestinal absorption [22]. Recently it has become clear that dAGEs contribute significantly to the body AGE pool. For the structural heterogeneity and the wide range of molecular weights of dAGEs, it is difficult to summarize their pharmacokinetics. Up today, limited studies have been conducted on few and selective compounds. For example fructoselysine, and lactulosyllysine (FruLys), mainly present in heated milk, are adsorbed passively through the intestinal mucosa $[8,23]$. Parts of them are degraded by microbiota, and a quote of $10 \%$ reaches the circulation, and they are mainly distributed in liver and muscle cells [8]. Also dietary ingested acrylamide is easily absorbed through the intestine tract, where it is rapidly metabolized and then excreted. However acrylamide and its metabolites can accumulate in the body when bounded to proteins in nervous system tissues or to hemoglobin in blood [24]. CML is widely measured as an index of AGEs in foods, although it can be also formed endogenously. Liardon et al. [25] assumed that the dietary CML is the main source of the urinary CML. Nearly its $10 \%$ is absorbed in the gastrointestinal tract and is delivered to liver and to other tissues. One third of this quote is excreted in the urine, and the remaining is accumulated in the body, leading to age-related damage [20]. Interestingly very recently Geissler et al. [26] showed that pyrraline, generated during the reaction of 3-deoxyglucosulose with lysine residues, was transported by $\mathrm{H}+-$ peptide co-transporter PEPT1 into intestinal cells. Also FruLys and CML have been demonstrated to bind to PEPT1, but with an inhibitory action [23].

Recent studies on human subjects have shown a significant increase in plasma AGE levels within two hours following the oral administration of a single AGE-rich meal [22]. Positive correlation between dAGE content and serum/tissue AGE levels have been also confirmed by several animal study $[17,27,28]$. For example Peppa et al. [29] to assess the role of dAGEs on type 1 diabetes, exposed the genetically susceptible NOD mice to a high-AGE diet and to a nutritionally similar diet with approximate fivefold-lower levels of CML and MG and demonstrated that after 44 weeks of treatment, NOD mice fed with Low-AGE diet showed almost half of serum AGE levels respect to High-AGE diet fed NOD mice. Moreover, Urribari et al. [30] demonstrated that dAGEs were correlated to the excess serum AGE levels found in diabetics and renal failure patients, contributing markedly to the total AGE pool in the body [11-13].

Circulating AGE levels reflect the equilibrium between exogenous/ endogenous AGE accumulation, their degradation and renal elimination. At tissue level, macrophages and other cellular systems endocytose and degrade AGEs via both receptor or non-receptor pathways, resulting in the formation of low molecular weight AGE peptides [31-34]. These peptides undergo a variable degree of reabsorption in the proximal nephron, while the rest is excreted in the urine. Therefore, effective elimination is dependent on normal renal function [31].

Then, at cellular level, there are intracellular protective systems which also limit the accumulation of reactive AGE derivatives. For instance, $\mathrm{MGO}$ is first converted by glyoxalase- $\mathrm{I}$ to $\mathrm{S}-\mathrm{D}$ lactoylglutathione and then to D-lactate by glyoxalase-II [35].

The above homeostatic systems, however, can be overwhelmed in high AGE conditions such as diabetes and renal failure, especially when combined with increased dAGE intake [34]. 
Citation: Abate G, Delbarba A, Marziano M, Memo M, Uberti D (2015) Advanced Glycation End Products (AGEs) in Food: Focusing on

\section{Biological effects of AGEs}

AGEs can exert their effects essentially by two different mechanisms. One is mediated by the interaction with specific receptors, and the other one is attributable to the direct cross-link to proteins, altering their structure and functions (Figure 1).

Among the AGE receptors the most studied is RAGE [36]. RAGE, a single trans-membrane multi-ligand receptor, belongs to the immunoglobulin superfamily, whose members include AGE-R, SR-A (macrophage scavenger receptor types I and II), and SR- B (SR-B type I and CD36) $[3,37]$.

RAGE receptors are physiologically mainly expressed on vascular, endothelial and smooth muscle cells and on monocyte/macrophage membranes [36,37]. The ligands of RAGE a part from AGEs and CML include also amyloid- $\beta$ peptide, members of the $S 100$ protein family, proteins of the high mobility group box-1 (HMGB1) and prions [38]

The interaction of RAGE receptors with AGEs induced the activation of different intracellular cascades, which involve Nuclear Factor-kappa Beta (NF- $\kappa \mathrm{B})$ pathway and inflammatory mediators like the tumor necrosis factor- $\alpha$ (TNF- $\alpha$ ), interleukin- 6 and C-reactive protein (CRP) [39]. The interaction of AGEs with RAGE receptors can also induce the gene expressions of leptin and its receptor that in turn activates intracellular signaling such as JAK2 and PI3K pathways. All these pathways lead to a pro- inflammatory status and to an increased oxidative stress.

Differently to RAGE, two receptors AGE-R1 and R3, belonged to immunoglobulin superfamily, once bound to AGEs activate protective pathways, involved in preventing ROS formation and activating AGE degradation and urinary excretion $[3,39]$.

Recently Cai et al. [40] showed that in mice fed with calorierestricted diet, AGE-R1 receptor expression enhanced, while the level of RAGE was unchanged, thus resulting in a high AGE-R1/RAGE ratio. In contrast, RAGE levels were enhanced in mice fed with highAGE diets and the AGE-R1/RAGE ratio was decreased with a corresponding increase in oxidative stress. Tang et al. [41] also demonstrated that AGEs could be directly involved in the divergent regulation of gene expression of RAGE and AGE-R1 in hepatic stellate cells, whose activation is fundamental for the development of hepatic fibrosis.

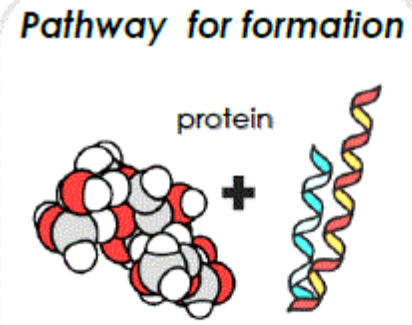

Sugar molecule

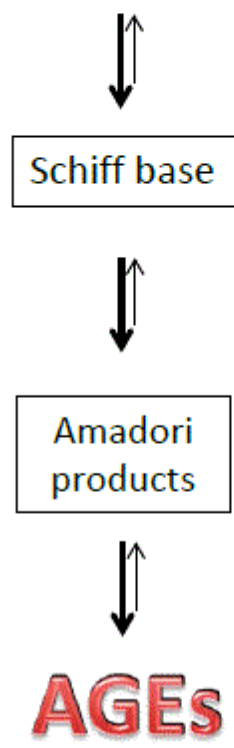

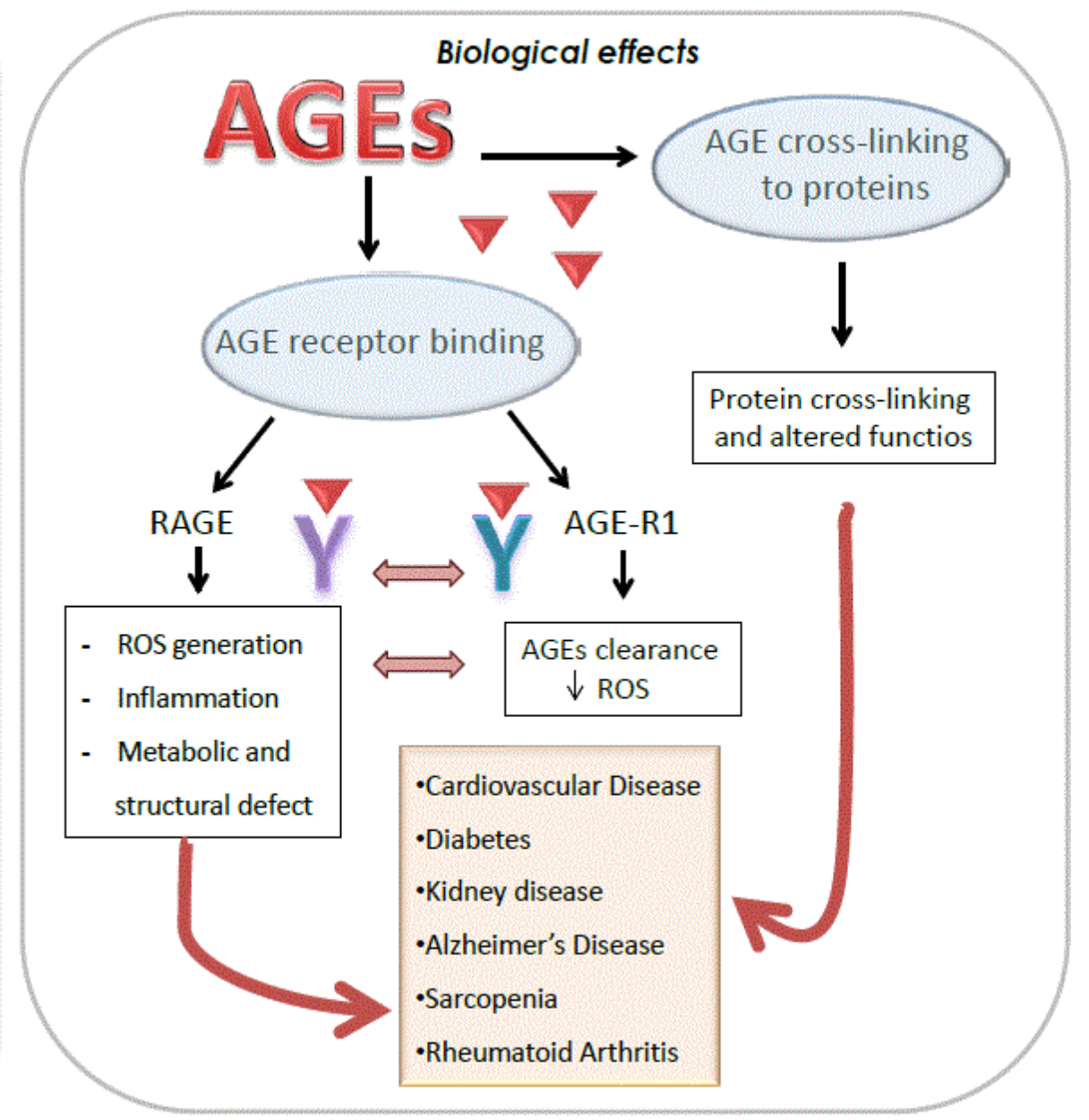

Figure 1: Schematic representation of AGEs formation and of their biological effects.

They hypothesized a vicious circle in which AGE-RAGE interactions activate the leptin intracellular signaling which leads to an increase of oxidative stress and that in turn facilitates the divergent regulation of gene expression of RAGE instead of AGE-R1. 
Interestingly, they also showed that bioactive nutrients such as Curcumin could prevent AGE-mediated toxic effects by interrupting leptin signaling and regulating gene expression of RAGE and AGE-R1. This suggests that AGE effects can be determined by the delicate balance between the expression of different antithetical receptors, influenced not only by genetic or pathological conditions but also by eating habits.

A very strong expression of RAGE and high levels of AGEs have been found in inflammatory conditions including osteoarthritis [42], and rheumatoid diseases such as rheumatoid arthritis and fibromyalgia [43]. Such increase affects especially tissues with a slow turnover, including tendons, bones, cartilage, and skin and could lead to the tissue stiffness and fragility in these structures [44].

Moreover, a strong association between RAGE-expression and AGE levels and the severity of Alzheimer's disease has been proposed by different authors [44-47].

The toxic effects of endogenous and exogenous AGEs result also from structural and functional alterations in plasma and extracellular matrix (ECM) proteins, in particular, from crosslinking of proteins (Figure 1). For example glucose pane is the most important cross-link products formed with ECM, known in human skin [48], and the glycated-myosin mainly affects myosin velocity and directionality [49]. Furthermore, AGE accumulation in collagen leads to changes in the biochemical and structural property of the components of the basement membrane affecting for example its elasticity, ionic charge, and thickness [50]. Accordingly, has been postulated that accumulation of AGE-crosslinking formed with vessel-wall collagen and basement membrane proteins, can contribute to vascular dysfunction [4,5]. In addition, AGE deposits have been found in atherosclerotic plaques and myocardium of patients with diabetes [2,52]. Immunohistochemical studies using anti-AGE antibodies have revealed the presence of AGE-modified proteins in several tissues under pathological conditions, including the kidneys of patients with diabetic nephropathy [52,53], chronic renal failure [54], and amyloid fibroids in hemodialysis-related amyloidosis [55].

All these findings stressed that AGEs can be considered as previously unrecognized dietary risk factors and important pathogenic mediators, involved in many age-related disorders. The discovery of natural AGE inhibitors and the adoption of an AGE-restricted diet could be a further new challenge in order to promote a healthy status.

\section{Mediterranean pasta}

Pasta is a highly popular cereal-based food produced worldwide because of its taste, convenience of use, ease of cooking and storage properties. Its consumption is recommended by Mediterranean dietary guidelines.

Pasta is prevalently constituted of carbohydrates and proteins. Its quality depends by different factors [56]. Evaluation of good pasta making starts from grain, but also the production processes can influence the quality of the final product.

For example moisture, starch content and protein percentage influence the features of the wheat for good pasta. Durum wheat, such as triticum turgidum, one of the hardest varieties of wheat, is the best to use for pasta-making because of its good cooking performance and stability to overcooking. The composition and the amount of protein content influence the pasta quality.
Protein content of durum wheat is characterized by two fractions soluble in water and in salt solution (albumins and globulins respectively), and two quotes extractable in aqueous ethanol solution or in dilute acid (gliadins and glutenins respectively) [56,57]. Low protein level confers low firmness, while high-protein durum wheat reduces cooking loss and improves texture with better performance in overcooking. Also the structure and amylose content of starch granules were found to influence pasta features.

On the other hand, among the different steps of pasta processing cycle, drying is crucial for the quality of end product. The traditional dry methods use low temperature from $45^{\circ}$ to $60^{\circ} \mathrm{C}$ for a long period of time, until $60 \mathrm{~h}$. While, the on large scale production increases by double the temperature (reaching $90-100^{\circ} \mathrm{C}$ ), shortening the drying process [58]. This technology brings benefit in term of productivity, cost, reliability, and reduction of microbial contamination. On the other hand, high temperature favors Maillard reactions with formation of stable Amadori compounds, which further evolved into stable AGE products. AGE product formation in pasta can be also favored by higher protein content and lower moisture in grain.

Thus, the AGE products can vary a lot depending by types of pasta (i.e., high or low protein amount, moisture, etc.) as well as by brand (i.e., production processes). Since especially CML has been used to commonly classify foods as an indicator of AGE burden in numerous animals and human studies, we measured CML content in 4 different pasta brands and in 3 different types of pasta: wheat, whole wheat and egg noodles. In details, different pasta samples were homogenized, dissolved in phosphate buffer saline and then tested for CML amount with an enzymatic-linked immuoassay based on monoclonal antiCML 4G9 antibody [6].

Results were expressed as kilo units (KU)/100 g of pasta. The majority of different brands of the different types of pasta showed a similar AGEs content (Table 1). These values are in line with those reported in the dietary AGE database published by Uribbari et al. [6].

\begin{tabular}{|c|c|c|c|}
\hline \multirow{2}{*}{ Samples } & Wheat & Whole Wheat & Egg Noodles \\
\cline { 2 - 4 } & & \multicolumn{2}{|c|}{ CML KU/100g } \\
\hline Brand 1 & $123 \pm 10,6$ & $185 \pm 11,2$ & $125 \pm 6,8$ \\
\hline Brand 2 & $69 \pm 5,3^{* *}$ & & $72 \pm 5,2^{* *}$ \\
\hline Brand 3 & $65 \pm 3,8^{* *}$ & & $68 \pm 3,4^{* *}$ \\
\hline Brand 4 & $128 \pm 8,4$ & & \\
\hline Brand 5 & & $152 \pm 7,9$ & \\
\hline Brand 6 & & $154 \pm 12,7$ & \\
\hline Brand 7 & & $230 \pm 15,3$ & \\
\hline Brand 8 & & & $123 \pm 7,5$ \\
\hline
\end{tabular}

Table1: CML content expressed as $\mathrm{KU} / 100 \mathrm{~g}$ of raw pasta in wheat, whole wheat and egg noodles. Results were given as mean \pm SEM values. Statistical significance of differences was determined by oneway ANOVA, followed by the Bonferroni test. ${ }^{* *} \mathrm{p}<0,001$ brand 2 and 3 vs the other ones.

However, there were two exceptions for two Italian brands (Table 1); whose wheat pasta and egg noodles expressed lower levels of CML content. Interestingly these products were dried at low temperature 
with a traditional method as reported by the manufacturer in the packaging. Furthermore, the AGE content in pasta obtained from whole unrefined grains was basically higher in comparison with wheat and egg noodles (Table 1).

This is probably due because the bran and the germ of grains contain the highest protein to carbohydrate ratio. In addition cooking time can significantly modify the AGE content in pasta. We conducted a series of experiments where different types of pasta were cooked for 9-11 min (depending on the period of time reported on the package to obtain an "al dente" palatability) or for additional $30 \%$ of the advised cooking times (overcooking). As reported in Figure 2, cooking significantly increased the amount of CML in all examined types of pasta in comparison with respective raw samples.

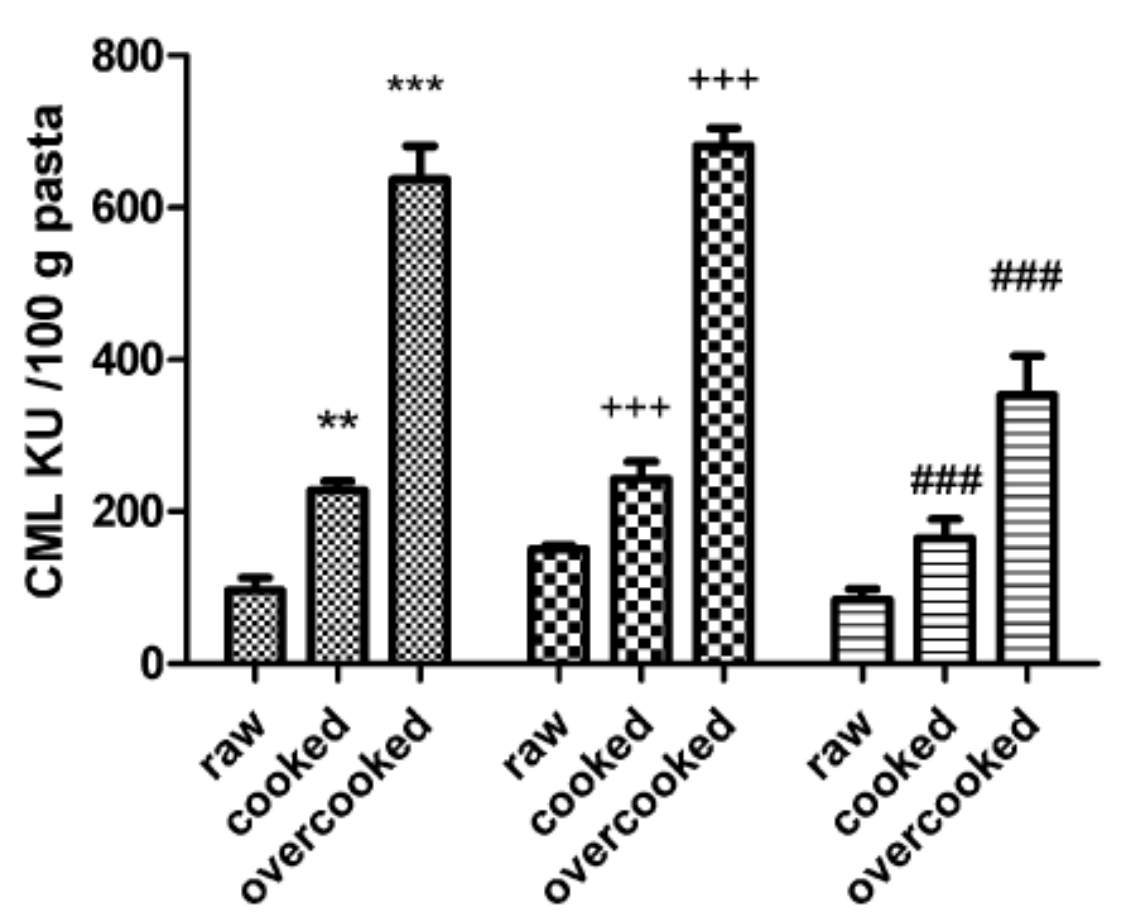

Figure 2: CML content analyzed in 3 different types of pasta at raw, cooked or overcooked. CML content was measured in 3 different types of pasta at raw, cooked or overcooked. Results were expressed as mean \pm S.E.M values of 4 different pasta brands of three different experiments. Statistical significance of differences was determined by one-way ANOVA, followed by the Bonferroni test. ${ }^{* *} \mathrm{p}<0,001$ cooked and ${ }^{* * *} \mathrm{p}<0,0001$ overcooked wheat vs raw wheat; $+++p<0,0001$ cooked and $+++p<0,0001$ overcooked whole wheat vs raw whole wheat; \#\#\#p<0,0001 cooked and \#\#\#p<0,0001 overcooked egg noodles vs raw egg noodles.

A dramatically increased of CML content was further observed with overcooking products. Among the overcooking products, egg noodles reported the lowest values of AGEs content in comparison with wheat and whole-wheat products, suggesting that the presence of egg nutrients might partially prevent AGE formation.

Especially fat soluble vitamin $\mathrm{E}$ and some minerals such as selenium present in eggs may exert an antioxidant effect, thus preventing oxidative degradation of sugar leading to AGEs formation. At this regards, it has been documented that antioxidant nutrient added to the base food can prevent the auto-oxidative pathways of AGE formation $[52,59,60]$.

Different surveys, analyzing food records from healthy individuals, reported that the mean daily AGE intake was around 15,000 \pm 5000 KU. These data could tentatively be used to define a high and low-AGE diet. Assuming that the mean consume of pasta per-capita in Italy is nearly $80 \mathrm{~g} /$ day; pasta can effectively be considered a low-AGE food. On the other hand cooking time can significantly modify its AGE content.
Some experiments conducted in our laboratory tried to highlight the biological relevance of pasta AGE content in function of cooking time, investigating its inflammatory and pro-oxidant effects. Initially to mimic the conditions at which food is exposed during the digestion, pasta extracts were incubated sequentially with different enzymes following the oral, then the gastric and finally the small intestinal digestion accordingly to Minekus et al. [61].

Human epithelial colorectal adenocarcinoma CACO2 cells were treated once a day for 3 consecutively days with different amount of digested protein extracts obtained from cooked or overcooked pasta. On the last day, cell cultures were processed for measuring IL-8 release and ROS production in conditioned medium and in cells respectively.

Cooked pasta did not modify IL-8 release and ROS production in cells at any examined concentration (Figure 3). Differently, when pasta was over-cooked its digested protein extracts induced an increase of ROS production and activated immune response with release of IL-8 at higher amounts (Figure 3).

Such effects were not of course comparable with those induced by LPS, but anyway are significant to note, taking into consideration the 
Page 6 of 8

repeated exposure that may induce potentially more toxic effects derived by AGEs accumulation.

\section{A}
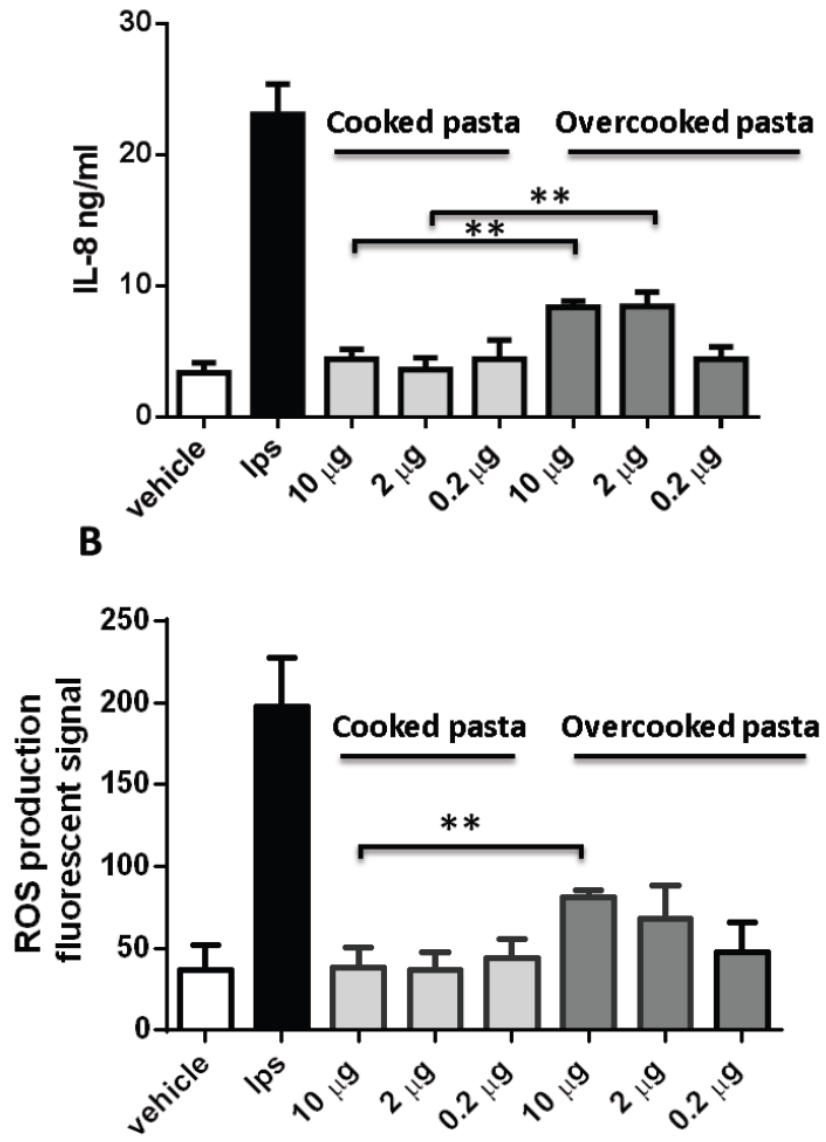

Figure 3: Effects of cooked and overcooked digested pasta extracts on IL-8 release and ROS production in CACO2 cells. Different amount of digested pasta extracts were added to confluent CACO2 cells ones a day for 3 days at different amounts. IL-8 release (A) and ROS production (B) were measured in the cells and conditioned media respectively. LPS was chosen as positive control, while digested solution without pasta protein extracts (vehicle) was the negative one. Statistical analysis was performed with one ANOVA test followed by Bonferroni test. IL-8 release: ${ }^{* *} \mathrm{p}<0,00110 \mu \mathrm{g}$ and 2 $\mu \mathrm{g}$ cooked vs $10 \mu \mathrm{g}$ and $2 \mu \mathrm{g}$ overcooked, respectively. ROS production: ${ }^{* *} \mathrm{p}<0,00110 \mu \mathrm{g}$ cooked vs $10 \mu \mathrm{g}$ overcooked.

Strategies to limit new dAGE formation in food should be adopted in order to limit AGEs intake. Through a reduced consumption of highly processed heat-treated foods, dietary AGE restriction may represent a relatively simple strategy to preserve healthy status and possibly, in a synergic optic, support pharmacological treatments for certain age-related disease like diabetes and renal disease.

\section{Acknowledgment}

This study was supported by Ministry of University and Research (MIUR) grants PAN LAB PON A3_00166.

\section{References}

1. Goldberg T, Cai W, Peppa M, Dardaine V, Baliga BS, et al. (2004) Advanced glycoxidation end products in commonly consumed foods. J Am Diet Assoc 104: 1287-1291.

2. Singh R, Barden A, Mori T, Beilin L (2001) Advanced glycation endproducts: a review. Diabetologia 44: 129-146.

3. Nedia O, Rattan SI, Grune T, Trougakos IP (2013) Molecular effects of advanced glycation end products on cell signalling pathways, ageing and pathophysiology. Free Radic Res 47 Suppl 1: 28-38.

4. Uribarri J, del Castillo MD, de la Maza MP, Filip R, Gugliucci A, et al. (2015) Dietary advanced glycation end products and their role in health and disease. Adv Nutr 6: 461-473.

5. Sebekova K, Somoza V (2007) Dietary advanced glycation endproducts (AGEs) and their health effects--PRO. Mol Nutr Food Res 51: 1079-1084.

6. Uribarri J, Woodruff S, Goodman S, Cai W, Chen X, et al. (2010) Advanced glycation end products in foods and a practical guide to their reduction in the diet. J Am Diet Assoc 110: 911-916.

7. Arribas-Lorenzo G, Morales FJ (2010) Analysis, distribution, and dietary exposure of glyoxal and methylglyoxal in cookies and their relationship with other heat-induced contaminants. J Agric Food Chem 58: 2966-2972.

8. Corzo-Martínez M, Avila M, Moreno FJ, Requena T, Villamiel M (2012) Effect of milk protein glycation and gastrointestinal digestion on the growth of bifidobacteria and lactic acid bacteria. Int J Food Microbiol 153: 420-427.

9. Han L, Li L, Li B, Zhao D, Li Y, et al. (2013) Review of the characteristics of food-derived and endogenous ne-carboxymethyllysine. J Food Prot 76: 912-918.

10. Henle T, Schwarzenbolz U, Klostermeyer H (1997) Detection and quantification of pentosidine in foods. Z Lebensm Unters Forsch 204: 95-98.

11. Vlassara H, Cai W, Crandall J, Goldberg T, Oberstein R et al. (2002) Inflammatory mediators are induced by dietary glycotoxins: A major risk factor for diabetic angiopathy. Proc Natl Acad Sci USA 99: 15596-15601.

12. Uribarri J, Peppa M, Cai W, Goldberg T, Lu M, et al. (2003) Restriction of dietary glycotoxins reduces excessive advanced glycation end products in renal failure patients. J Am Soc Nephrol 14: 728-731.

13. Uribarri J, Peppa M, Cai W, Goldberg T, Lu M, et al. (2003) Dietary glycotoxins correlate with circulating advanced glycation end product levels in renal failure patients. Am J Kidney Dis 42: 532-538.

14. Vlassara H, Cai W, Goodman S, Pyzik R, Yong A, et al. (2009) Protection against loss of innate defenses in adulthood by low advanced glycation end products (AGE) intake: role of the antiinflammatory AGE receptor-1. J Clin Endocrinol Metab 94: 4483-4491.

15. Lee TC, Kimiagar M, Pintauro SJ, Chichester CO (1981) Physiological and safety aspects of Maillard browning of foods. Prog Food Nutr Sci 5: 243-256

16. Camire ME (1995) Chemical changes during extrusion cooking. In: Shahidi F, Ho CT, van Chuyen N, eds. Process Induced Chemical Changes in Food. New York, NY: Plenum Press 109-119.

17. Lin RY, Reis ED, Dore AT, Lu M, Ghodsi N, et al. (2002) Lowering of dietary advanced glycation endproducts (AGE) reduces neointimal formation after arterial injury in genetically hypercholesterolemic mice. Atherosclerosis 163: 303-311

18. Nagai R, Shirakawa J, Ohno R, Moroishi N, Nagai M (2014) Inhibition of AGEs formation by natural products. Amino Acids 46: 261-266.

19. Dearlove RP, Greenspan P, Hartle DK, Swanson RB, Hargrove JL (2008) Inhibition of protein glycation by extracts of culinary herbs and spices. J Med Food 11: 275-281. 
20. Semba RD, Ang A, Talegawkar S, Crasto C, Dalal M et al. (2012) Dietary intake associated with serum versus urinary carboxymethyl-lysine, a major advanced glycation end product, in adults: the Energetics Study. Eur J Clin Nutr 66: 3-9.

21. Uribarri J, Cai W, Peppa M, Goodman S, Ferrucci L, et al. (2007) Circulating glycotoxins and dietary advanced glycation endproducts: two links to inflammatory response, oxidative stress, and aging. J Gerontol A Biol Sci Med Sci 62: 427-433.

22. Koschinsky T, He CJ, Mitsuhashi T, Bucala R, Liu C, et al. (1997) Orally absorbed reactive glycation products (glycotoxins): an environmental risk factor in diabetic nephropathy. Proc Natl Acad Sci U S A 94: 6474-6479.

23. Grunwald S, Krause R, Bruch M, Henle T, Brandsch M (2006) Transepithelial flux of early and advanced glycation compounds across Caco-2 cell monolayers and their interaction with intestinal amino acid and peptide transport systems. Br J Nutr 95: 1221-1228.

24. Amrein TM, Andres L, Escher F, Amadò R (2007) Occurrence of acrylamide in selected foods and mitigation options. Food Addit Contam 24 Suppl 1: 13-25.

25. Liardon R, De Weck-Gaudard D, Philippossian G, Finot PA (1987) Identification of N. epsilon. carboxymethyllysine: a new Maillard reaction product in rat urine. J Agric Food Chem 35: 427-431.

26. Geissler S, Hellwig M, Zwarg M, Markwardt F, Henle T, et al. (2010) Transport of the advanced glycation end products alanylpyrraline and pyrralylalanine by the human proton-coupled peptide transporter hPEPT1. J Agric Food Chem 58: 2543-2547.

27. Sandu O, Song K, Cai W, Zheng F, Uribarri J, et al. (2005) Insulin resistance and type 2 diabetes in high-fat-fed mice are linked to high glycotoxin intake. Diabetes 54: 2314-2319.

28. Zheng F, He C, Cai W, Hattori M, Steffes M, et al. (2002) Prevention of diabetic nephropathy in mice by a diet low in glycoxidation products. Diabetes Metab Res Rev 18: 224-237.

29. Peppa M, He C, Hattori M, McEvoy R, Zheng F, et al. (2003) Fetal or neonatal low-glycotoxin environment prevents autoimmune diabetes in NOD mice. Diabetes 52: 1441-1448.

30. Uribarri J, Cai W, Sandu O, Peppa M, Goldberg T et al. (2005) Dietderived advanced glycation end products are major contributors to the body's AGE pool and induce inflammation in healthy subjects. Ann N Y Acad Sci 1043: 461-466.

31. Vlassara H, Palace MR (2002) Diabetes and advanced glycation endproducts. J Intern Med 251: 87-101.

32. Peppa M, Uribarri J, Vlassara H (2002) Advanced glycoxidation. A new risk factor for cardiovascular disease? Cardiovasc Toxicol 2: 275-287.

33. Peppa M, Uribarri J, Vlassara H (2004) The role of advanced glycation end products in the development of atherosclerosis. Curr Diab Rep 4: 31-36.

34. Peppa M, Vlassara H (2005) Advanced glycation end products and diabetic complications: a general overview. Hormones (Athens) 4: 28-37.

35. Shinohara M, Thornalley PJ, Giardino I, Beisswenger P, Thorpe SR, et al. (1998) Overexpression of glyoxalase-I in bovine endothelial cells inhibits intracellular advanced glycation endproduct formation and prevents hyperglycemia-induced increases in macromolecular endocytosis. J Clin Invest 101: 1142-1147.

36. Bierhaus A, Humpert PM, Morcos M, Wendt T, Chavakis T, et al. (2005) Understanding RAGE, the receptor for advanced glycation end products. J Mol Med (Berl) 83: 876-886.

37. Boyer F, Vidot JB, Dubourg AG, Rondeau P, Essop MF, et al. (2015) Oxidative stress and adipocyte biology: focus on the role of AGEs. Oxid Med Cell Longev 2015: 534873.

38. Basta G (2008) Receptor for advanced glycation endproducts and atherosclerosis: From basic mechanisms to clinical implications. Atherosclerosis 196: 9-21.

39. Younessi P, Yoonessi A (2011) Advanced glycation end-products and their receptor-mediated roles: inflammation and oxidative stress. Iran J Med Sci 36: 154-166
40. Cai W, He JC, Zhu L, Chen X, Wallenstein S, et al. (2007) Reduced oxidant stress and extended lifespan in mice exposed to a low glycotoxin diet: association with increased AGER1 expression. Am J Pathol 170: 1893-1902.

41. Tang Y, Chen A (2014) Curcumin eliminates the effect of advanced glycation end-products (AGEs) on the divergent regulation of gene expression of receptors of AGEs by interrupting leptin signaling. Lab Invest 94: 503-516.

42. DeGroot J, Bank RA, Bijlsma JWJ, TeKoppele JM, Verzijl N et al (2004) Advanced glycation end products in the development of osteoarthritis. Arthritis Res Ther 6: 78.

43. Hein GE, Kohler M, Oelzner P, Stein G, Franke S (2005) The advanced glycation end product pentosidine correlates to IL- 6 and other relevant inflammatory markers in rheumatoid arthritis. Rheumatol Int 26: 137-141.

44. Bengmark S (2007) Advanced glycation and lipoxidation end products-amplifiers of inflammation: the role of food. JPEN J Parenter Enteral Nutr 31: 430-440.

45. Smith MA, Richey PL, Taneda S, Kutty RK, Sayre LM, et al. (1994) Advanced Maillard reaction end products, free radicals, and protein oxidation in Alzheimer's disease. Ann N Y Acad Sci 738: 447-454.

46. Moreira PI, Smith MA, Zhu X, Nunomura A, Castellani RJ, et al. (2005) Oxidative stress and neurodegeneration. Ann N Y Acad Sci 1043: $545-552$

47. Lue LF, Yan SD, Stern DM, Walker DG (2005) Preventing activation of receptor for advanced glycation endproducts in Alzheimer's disease. Curr Drug Targets CNS Neurol Disord 4: 249-266.

48. Monnier VM, Sun W, Sell DR, Fan X, Nemet I, et al. (2014) Glucosepane: a poorly understood advanced glycation end product of growing importance for diabetes and its complications. Clin Chem Lab Med 52: 21-32.

49. Ramamurthy B, Jones AD, Larsson L (2003) Glutathione reverses early effects of glycation on myosin function. Am J Physiol Cell Physiol 285: C419-424.

50. Reddy GK (2004) Cross-linking in collagen by nonenzymatic glycation increases the matrix stiffness in rabbit achilles tendon. Exp Diabesity Res 5: 143-153.

51. Goldin A, Beckman JA, Schmidt AM, Creager MA (2006) Advanced glycation end products: sparking the development of diabetic vascular injury. Circulation 114: 597-605.

52. Rahbar S, Figarola JL (2003) Novel inhibitors of advanced glycation endproducts. Arch Biochem Biophys 419: 63-79.

53. Makino H, Shikata K, Kushiro M, Hironaka K, Yamasaki Y, et al. (1996) Roles of advanced glycation end-products in the progression of diabetic nephropathy. Nephrol Dial Transplant 11 Suppl 5: 76-80.

54. Yamada K, Miyahara Y, Hamaguchi K, Nakayama M, Nakano H, et al. (1994) Immunohistochemical study of human advanced glycosylation end-products (AGE) in chronic renal failure. Clin Nephrol 42: 354-361.

55. Miyata T, Oda O, Inagi R, Iida $\mathrm{Y}$, Araki N, et al. (1993) beta 2Microglobulin modified with advanced glycation end products is a major component of hemodialysis-associated amyloidosis. J Clin Invest 92: 1243-1252.

56. Sicignano A, Di Monaco R, Masi P, Cavella S (2015) From raw material to dish: pasta quality step by step. J Sci Food Agric 95: 2579-2587.

57. Osborne TB (1907) The Proteins of the Wheat Kernel. Carnegie Institution of Washington, Washington, DC.

58. Giannetti V, Mariani MB, Mannino P (2013) Furosine as a pasta quality marker: evaluation by an innovative and fast chromatographic approach. J Food Sci 78: C994-999.

59. Brewer MS (2011) Natural Antioxidants: Sources, Compounds, Mechanisms of Action, and Potential Applications. CRFSFS 10: 221-247.

60. Jahan H, Choudhary MI (2015) Glycation, carbonyl stress and AGEs inhibitors: a patent review. Expert Opin Ther Pat 25: 1267-1284. 
Citation: Abate G, Delbarba A, Marziano M, Memo M, Uberti D (2015) Advanced Glycation End Products (AGEs) in Food: Focusing on Mediterranean Pasta. J Nutr Food Sci 5: 440. doi:10.4172/2155-9600.1000440

Page 8 of 8

61. Minekus M, Alminger M, Alvito P, Ballance S, Bohn T, et al. (2014) A standardised static in vitro digestion method suitable for food - an international consensus. Food Funct 5: 1113-1124. 